\title{
Flood warnings in coastal areas: how do experience and information influence responses to alert services?
}

\author{
G. Pescaroli ${ }^{1}$ and M. Magni ${ }^{2}$ \\ ${ }^{1}$ Institute for Risk and Disaster Reduction, University College London, London, UK \\ ${ }^{2}$ Università Politecnica delle Marche, Ancona, Italy \\ Correspondence to: G. Pescaroli (gianluca.pescaroli.14@ucl.ac.uk)
}

Received: 16 September 2014 - Published in Nat. Hazards Earth Syst. Sci. Discuss.: 21 January 2015

Revised: - - Accepted: 19 March 2015 - Published: 1 April 2015

\begin{abstract}
Many studies discuss the economic and technical aspects of flood warnings. Less attention has been given to the social and behavioural patterns that affect alert services. In particular, the literature focuses on warnings activated in river basins or marine environments without providing clear evidence on Mediterranean coastal areas, even though these are subjected to growing flood risk related to climate change. This paper is a first attempt to bridge this gap. Our research develops an in-depth analysis of the village of Cesenatico on the Adriatic Sea coast. Here the municipality adopted two complementary warning systems: a siren and an alert via short message service (SMS). The analysis focuses on a survey conducted in 2011 and 2012 with 228 participants. The relationships between social and behavioural variables and warning services are investigated as well as flood preparedness and information dissemination. Qualitative evidence from informal interviews is used to support the understanding of key responses. The conclusions show how different social and behavioural patterns can influence the effectiveness and use of warning systems, regardless of the technology adopted and the structural mitigation measures implemented. Education, training and accountability are seen to be critical elements for implementation. Finally, the statistical output is used to suggest new questions and new directions for research.
\end{abstract}

\section{Introduction}

Anyone committed to the creation of a safer society knows how critical the challenge represented by floods is. In 2012, they resulted in $53 \%$ of all disaster victims (the sum of deaths and total affected people) and represented 6 out of the 10 worst events in the same category. For example, the flood that struck China in June 2012 caused 17.4 million victims alone (Guha-Sapir et al., 2013). Increasing pressure on the environment and the possible effects of climate change further highlighted the need for innovative mitigation and resilience strategies. In particular, warning plays a crucial role in the disaster cycle as one of the means of reducing the effects of hazards. It can be defined as risk communication about an imminent event that is intended to produce appropriate reactions in citizens (Lindell et al., 2007). Intuitively, anyone can think of a large number of situations in which the presence of an alert could make the difference between life and death. This is particularly true for floods. According to the Encyclopedia of Natural Hazards (2012), "a natural warning system is usually technology based, monitors signs of a natural hazard, evaluates the signs against rules and notifies people, triggering a human response" (Leonard et al., 2012, p. 1091). However, they have to be contextualized to be effective. Alexander (1993, p. 400) noted that the creation and implementation of warnings "involves the complex interactions between physical, technological and social systems whose operation must be carefully coordinated in order to achieve a satisfactory result."

Flood warnings are based not only on technical elements (the technology used for forecasting and monitoring hazards or the solutions used to disseminate advice) but also on the community, which receives and responds to them. Many studies, such as that by Tapsell (2010), show that flood warnings orientate individual actions during the preparedness and response phases. Timely, focused and widespread warnings can determine both the effectiveness of mass-response mea- 
sures, such as evacuation plans, and the adoption of individual measures, such as safety measures in households. If these are inadequate, they can increase the perceived impacts of flooding in groups in which communication is lacking (Penning-Rowsell and Tapsell, 2002), while the same poor performances also exacerbate the intangible impact of floods (Penning-Rowsell et al., 2000). Even if those points seem to be self-evident, for many years flood policies concentrated on structural mitigation measures, such as the construction of dikes and other physical barriers.

The definitive adoption of flood risk management, which includes an emphasis on non-structural elements, has occurred only since the early 1990s. This period saw the development of a mix of mitigation measures that increasingly used behavioural approaches to reduce human vulnerability to floods but, for a long time, maintained a top-down approach. In the past, emphasis on technological solutions for monitoring river or sea levels has generally not been followed by the development of appropriate warning dissemination strategies (Gruntfest, 2000). Similarly, 1697 interviews conducted after the 2002 floods with private residents located in the River Elbe and Danube catchments showed that more than a quarter of the people did not receive any warning at all. Flood warning given by the authorities reached $41 \%$ of people interviewed, but $33 \%$ of citizens became aware of flooding through their own observations, while personal networks (friends, neighbours and relatives) contributed $13 \%$. The advice given by nationwide news broadcasts contributed only $14 \%$ (Thieken et al., 2007). Smith and Petley (2009) observed similar patterns during the June 2007 flooding in the UK: many problems occurred in south and east Yorkshire, in particular at Sheffield, Doncaster and Hull, where residents were unprepared and failed to receive appropriate warnings. This could be framed in what Handmer (2001) defined as "a failure in the conceptualization of the warning task", where agencies acquired an authoritarian position rather than recognizing that floods are "owned" by the communities in which they occur. According to this view, warnings remain more a function of relief services than an artefact of the longterm empowerment of communities. Different levels of governance were often in conflict, which reduced the opportunities for co-operative action.

Although the situation seems to have changed slightly in recent years, quantitative and qualitative research carried out in Finland, Ireland, Italy and Scotland by O'Sullivan et al. (2012) has demonstrated that many problems still remain. Low levels of the understanding of terminology on flood magnitude were perceived as cross-national patterns, while communication usually failed to channel direct, brief and focused messages. Nevertheless, improvements in the general framework of warning processes seem to be possible. Parker and Priest (2012) noted that in many European countries, concrete steps have been taken to increase the accessibility of information and to differentiate communication channels. Traditional instruments, in which agencies directly release and disseminate warnings through face-to-face advice or sirens, have been implemented and integrated with modern communication and information technologies. New forms of "pull" warnings have been activated and are based on the active role of citizens, for example by accessing online instruments (web pages) or through a request to the provider by a telephone call. However, is this true everywhere, and how do different systems interact with each other from a social and behavioural perspective?

The current state of European flood warnings is mostly based on evidence derived from the United Kingdom and by Germany. The majority of the literature analysed flood warnings at large, with references to both riverine and coastal flooding, for example in official reports by the UK ministry DEFRA (Fielding et al., 2007). A large number of studies referred directly to river floods, but for the Mediterranean area it was not possible to find systematic evidence that included a cross-cutting analysis of demographic factors, local experiences, public perceptions of information levels, risk information, data on damage and how all of these influence specific warning systems. On the one hand, there are interesting studies, such as the one by Lara et al. (2010), that widely analyse social perceptions of floods but that do not include specific analyses of warning services. On the other hand, technical elements of warnings, such as those related to organization or monitoring, often prevail in literature.

Llasat and Siccardi (2010) proposed a means of integrating the social and technological aspects and increasing the effectiveness of flood risk management. These authors argued that for a modern civil protection service, a particular challenge is how to improve the reliability of warning systems, which in the Mediterranean can still be affected by technological uncertainties inherent in the forecasting and prediction processes. Thus, many questions are still open and cannot be satisfied by a straightforward review of literature. Three points are central to our work:

- In coastal area subject to recurring flooding, how can social and behavioural patterns orientate the effectiveness of specific warning instruments?

- Can a warning system be perceived as useful from the technical point of view but lose its potential if the social dimension is missing?

- Is there any difference between the dynamics of the situation in the Mediterranean and those reported in the literature?

In order to make use of a broad range of data, we carried out an in-depth analysis of the village of Cesenatico on the northern Italian Adriatic coast: the region was subject to increased surge frequency and an early warning system was recently implemented by MICORE project (Ciavola et al., 2011). In particular, the site of Cesenatico was distinguished by a wellknown history of flooding, diffuse perception of flood risk 


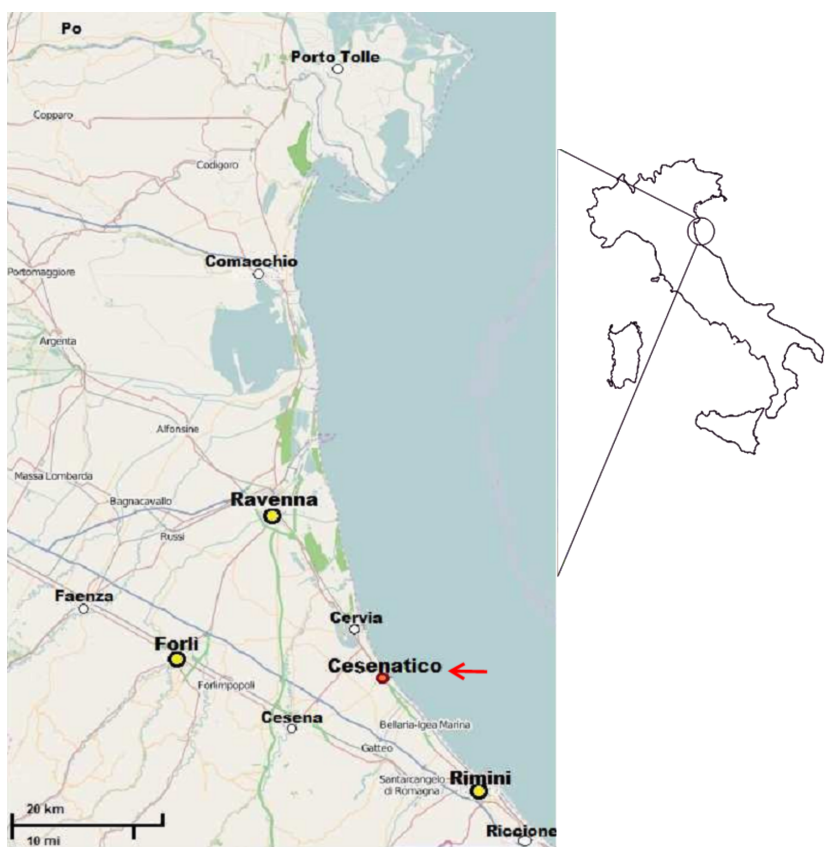

Figure 1. Location of Cesenatico on the coast of Emilia-Romagna and its position in Italy. The yellow points represent the three biggest cities in the area, while the white ones highlight some of the other large municipalities nearby (source: our elaboration from Open Street Map).

and the presence of two complementary warning systems, namely a siren and an alert via short message service (SMS) that sent notifications when the siren was activated.

\section{Description of Cesenatico and local flood risk}

Cesenatico is an important tourist destination near the cities of Rimini and Ravenna (Fig. 1). It is well known for its sandy beaches and the attractiveness of its recreational activities. According to official statistics issued by the Italian National Institute of Statistics (ISTAT) and the Regional Government of Emilia-Romagna, in 2013 the municipality of Cesenatico had 25686 inhabitants (12433 males and 13253 females), of which 4212 were under 18 years old (16\%), 16029 were between 18 and 64 years old $(62 \%)$ and 5445 were over 65 years old $(21 \%)$. The mean age was 43.8 years. According to the detailed demographic and residential profile, the residents of the main town, excluding hamlets, numbered 10116 . However, this refers to the 2001 official population census and 2011 data are still under development by ISTAT. In economic terms, tourism is the mainstay of Cesenatico. As the provincial administration of ForlìCesena (2013) noted, there is an average of 474582 arrivals per year and average stay of 8 days each. The region in which Cesenatico lies is distinguished by the highest social capital in Italy and in the past had been taken as a reference for the

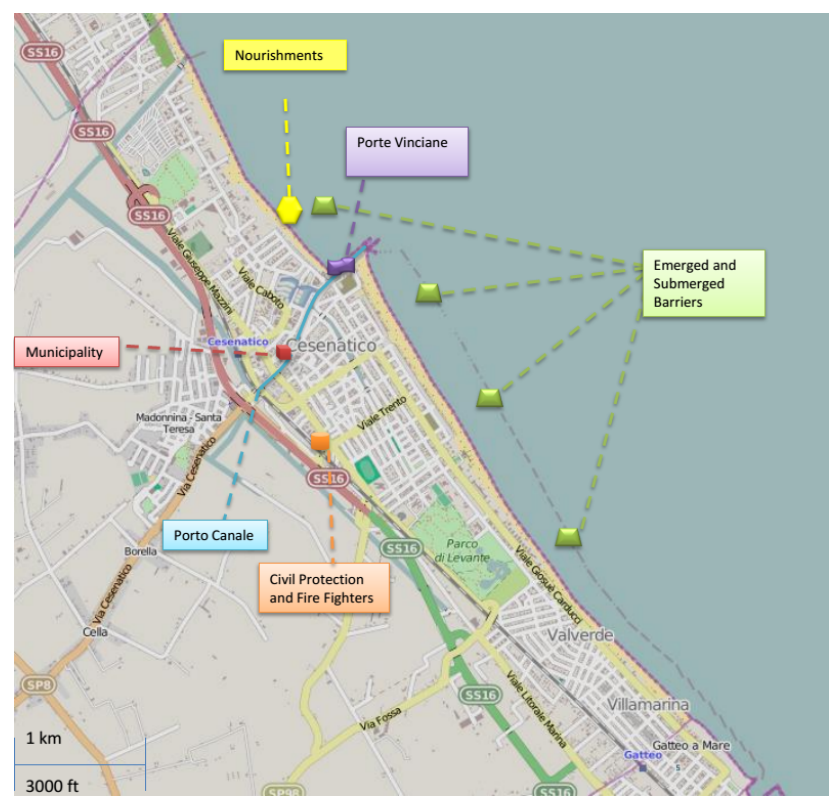

Figure 2. Map of Cesenatico. We highlighted the location of the Porto Canale, the municipality and the key emergency actors (civil protection and fire fighters). Furthermore, we included the location of some of the structural defences and sand nourishments (source: our elaboration from Open Street Map).

relationship between good governance and democracy (Putnam et al., 1993). Local social capital includes some of the highest numbers of sport societies and their members per 1000 inhabitants but a slightly lower value of participation in blood donation drives and the lowest number of newspapers per 1000 citizens in the region (Cartocci, 2007). Voter activity in the 2011 municipal elections was $72.72 \%$, in line with average figures for the Emilia-Romagna region $(71.5 \%)$ and slightly higher than the national value $(68.3 \%)$. From this overview, what emerges is a strong and active community, in which relationships matter but voluntary activities may be somewhat limited. The lower rate of diffusion of newspapers may imply that traditional sources of information, and associated channels of dissemination, do not have a strong hold on this area.

The coastline of Cesenatico is approximately $7 \mathrm{~km}$ long and is divided by harbour jetties and defences into a northern and southern area (Fig. 2). In the last 50 years, the northern areas known as Cesenatico Ponente and Cesenatico Colonie have been subject to strong erosion that gradually consumed the beach that separates the sea from coastal buildings (Regione Emilia Romagna, 2011a). Indeed, Martinelli et al. (2010) pointed out that the municipality is part of a strongly urbanized littoral where a general erosive tendency can be associated with the reduced sediment transport rates of the rivers and the increased anthropogenic subsidence. According to the same authors, the building of tourism facilities contributed as well to the alteration of the beach equilibrium. 
The flood history of Cesenatico differs from that of the areas in which most studies have been focused, such as the coasts and rivers of England. Early attempts to protect the harbour against floods date to $1502 \mathrm{AD}$. At the time, siltation was a constant problem, and none other than Leonardo Da Vinci planned a solution. He modified the orientation and length of palings, extended the adjacent basin and regulated the water flow with a system of mobile bulkheads system called Porte Vinciane. Similarly, his plans were used to create Porto Canale, a main water canal that divides the city centre and is still used as a harbour. Nowadays, the municipality is subject to a growing flooding risk related to the dynamics of climate change, urban development and technical problems of water basin management. When bad weather occurs in conjunction with sea surges channels are likely to overflow despite the technical solutions adopted. Armaroli et al. (2012) recorded 27 extreme marine events that hit the regional coast between 1966 and 2008. The storms were mostly associated with high surge levels and were typical of the winter period. They caused widespread damage such as inundation of the backshore, strong beach erosion and destruction or damage to properties. A peak in damage was related to canal and harbour overflow within the municipality of Cesenatico (Perini et al., 2011). In the last 20 years the main events recoded in Cesenatico occurred in 1996, 1997, 1999 and 2004 (Perini et al., 2011). The flood of 1996 was the first emergency mobilization for the local group of civil protection volunteers (Radio Soccorso Cesenatico), which was established only a few years before. In early 2011, about 1000 people were involved and nearly 400 buildings were damaged (Il Giornale della Protezione Civile, 2011). Many minor events have been recurrent in local history, but a full list is not presented in this paper. However, it can be pointed out that local floods are distinguished by economic and structural damages rather than loss of life, which is relatively rare.

Since 1978, a large number of modifications have sought to ensure the safety of the coast but without satisfactory results. The official documentation by Regione Emilia Romagna (2011b) explained this process: the measures included Longard pipes, submerged sandbag barriers, beach nourishment and rock panels. During the 1980s and 1990s, around $800 \mathrm{~m}$ of coastline near the bathing establishments was maintained with repeated beach nourishment, followed by other cases of beach nourishment in the northern area known as the Zona delle Colonie until this activity ceased at the end of the 1990s. A major defence of emerged shores from the harbour of Rimini to that of Cesenatico was completed in 1997. This measure has had particular collateral effects, as it intercepts most sediment along the coast: it has recently been understood that in the future, through its effects, the beach of north Cesenatico will be maintained only with artificial relocation of sand. Finally, a new parallel cliff barrier was built in the year 2000 to protect the bathing establishments (Regione Emilia Romagna, 2011b). In the most recent years, new harbour gates have been built to protect Porto Canale, but many technical problems have occurred and reduced their effectiveness. In addition, the authorities have increased the monitoring of Porto Canale and provided local civil protection services with real-time information. Two different warning systems have been adopted: a siren, located in the Porto Canale area, and warning advice sent by SMS. The SMS is a free service based on voluntary registration. It is triggered when the siren is activated and is therefore complementary to the latter. It is important to note that some groups of citizens have the duty to call other people when they hear the siren.

\section{Methodological background}

The methodology adopted is mainly quantitative, but a qualitative approach was used to support the data set by providing a wider interpretation of its social context. The study is based on a five-page questionnaire distributed in Cesenatico during March 2011 (after the flood of that year) and May 2012. It aimed to explore the local perceptions of risk and preparation, to allow in-depth analysis of different features such as the cultural setting and to probe the experience of the community and the personal history of individuals. It included specific questions on warnings and required nearly $15 \mathrm{~min}$ to be completed. Two core sections sought to obtain fundamental data on warnings, as follows:

1. Respondents were asked to provide their level of preparedness according to a 10 -item Likert scale. Specific statements to be responded included the perception of information about flood risk in Cesenatico $(1=$ not informed at all, $10=$ extremely well informed); declaration of preparedness level for surviving a flood in Cesenatico $(1=$ not prepared at all, $10=$ extremely well prepared); perception of capacity for self-protection $(1=$ not able at all, $10=$ extremely able $)$; knowledge of the mobile alert service created by the municipality (yes or no); and its perceived utility $(1=$ not useful at all, $10=$ very useful). The questionnaire finally asked how many times the flood alert siren was heard and the respondents' reactions upon hearing it.

2. Past experience of flooding was enquired by questions with scaled answers that ranged from 1 to 10 . They focused on financial damage caused by previous flooding ( $1=$ no financial damage, $10=$ considerable damages $)$; on how much ordinary life had been disrupted $(1=$ no disruption at all, $10=$ considerable disruption); and the perceived effectiveness of emergency responses by the Port Authority, fire fighters, civil protection, the municipality and the emergency medical services $(1=$ not effective at all, $10=$ completely effective).

Participants were recruited in the Porto Canale area, or in its immediate proximity, with direct contact in the streets, at the seaside or in the shops according to the methodologi- 
cal features of "intercept interviews". This method was chosen because of observed local behaviour, where face-to-face contact and dialogue is more likely to produce effective collaboration with the research than would phone interviews or online questionnaires. In particular, the Porto Canale area is considered a distinctive feature of Cesenatico, a spatial "node" where all the cultural, community and geographical patterns interact with each other. On the one hand, institutions such as the municipality and associations such as Confesercenti (the national association of businesses) have their offices there. On the other hand, the area is characterized by the diffuse presence of commercial activities such as shops, restaurants and bars, but it is also subject to recurring floods. A random sampling strategy targeting subjects who meet the following parameters was applied to ensure that everyone has the same probability of being selected (Phillips, 2014):

1. Residents or regular workers in Cesenatico: this limitation was needed in order to ensure an effective perception of risk and its countermeasures while assuring that the respondents were likely to have had local experience of flooding.

2. Over 18 years old: this element referred to the legal age of maturity in Italy and to full, independent involvement in the rights and responsibilities of citizenship.

A mixed-mode approach was used to integrate paper-based questionnaires and face-to face interviews (De Leeuw, 2005). Data were collected and the overall methodology was developed according to the criteria for quantitative procedures (Tabachnick and Fidell-Allyn, 2006). Specific statistical tests were performed to obtain coherent and replicable results. Data sets were checked to find out which tests were adequate and which assumptions could be satisfied. Since data were not normally distributed, non-parametric tests were selected either to explore relationships among categorical and continuous variables (Spearman's rank-order correlation, chisquare test for independence) or to compare groups (MannWhitney $U$ test, Kruskal-Wallis test). Where appropriate, post-hoc analysis was performed to deepen the statistical significant differences among groups (Jonckheere trend test, Mann-Whitney $U$ test with Bonferroni correction). Qualitative methodology, such as direct observation and informal interviews (Russell-Bernard, 2006), were used to support the interpretation of questionnaire results with a proper understanding of any local dynamics that could affect the choices and perceptions of respondents. In our case, qualitative methods were employed after the questionnaire interviews had been conducted. Field notes were developed during the interviews, or immediately after, and were consolidated on a daily basis, while in some cases, in agreement with respondent, the "comment" space of the questionnaire was used.

\section{Results}

This section describes the results of our research. First, we provide a short contextualization of the analysis (demographics, perceived level of preparedness and structural mitigation measures), where we focus on information and experience intended as central aspects that can influence the capacity to react to warning systems. Second, we present the specific results for the alert siren and the SMS warning service and correlate them with the contextual drivers.

\subsection{Context, information and experience}

In total, 228 questionnaires were completed. The majority of them $(73 \%)$ were self-administered. Some $54 \%$ of the respondents were males and $45 \%$ were females. The average age was 40.2 years $(\mathrm{SD} \pm 14.3)$. Participants had a medium level of education, as $25 \%$ of them had a middleschool diploma, $62 \%$ had a high-school diploma and $13 \%$ a degree. Some $31 \%$ owned a business near the seaside, while $46 \%$ worked in related activities. Finally, $45 \%$ lived near the seaside. Respondents did not feel adequately prepared to cope with flood risk $(M=4)$, but they felt significantly more able to protect themselves and their families during a hypothetical event $(\operatorname{Mdn}=5), z=-4.18, p<0.001$. These variables were also positively correlated, $r_{s}=0.63$, $p<0.001$. Structural protection barriers were generally evaluated to be insufficiently effective, and this is likely to be influenced by the perception of local flood history of the interviewees. In particular, this applied to the new harbour gates $(M=3.58, \mathrm{SD} \pm 2.52)$ and the submerged barriers $(M=4.23, \mathrm{SD} \pm 2.44)$. Similarly, the transverse rocky barriers $(M=4.43, \mathrm{SD} \pm 2.38)$ and sand nourishment were not considered sufficient $(M=5.02, \mathrm{SD}=2.65)$.

The interviewees did not feel adequately informed about flood risk in Cesenatico $(M=4.3, \mathrm{SD} \pm 2.70)$. Nevertheless, the more the respondents felt informed, the more they tend to consider themselves prepared to face a flood $\left(r_{s}=0.40\right.$, $p<0.001)$ and to take care of their families during such an event $\left(r_{s}=0.34, p<0.001\right)$. Even though only a minority of them $(14 \%)$ made no effort to search for information about flooding, the results highlight a lack of direct official communication from the authorities and put the level of education and training activities in the community as almost irrelevant. Indeed, only $11 \%$ of respondents reported the port authority's advice as their only source of information, and it was associated to other sources by a further $6 \%$ (i.e. $17 \%$ depended to some extent on it). The role of drills as information sources was noted only by $1 \%$ of the respondents. Instead of focusing on a single communication channel for the dissemination process, the need to use many different sources was poorly appreciated, and respondents variously relied on the Internet (13\%), word of mouth (12\%), newspapers (10\%), television $(5 \%)$ and other means $(5 \%)$. Some $30 \%$ of all participants used two or more sources together, and this reached only 
$44 \%$ if only people searching for information are considered. Only $38 \%$ were aware of possible routes and methods of evacuation, while $62 \%$ were unaware. Informal interviews highlighted the lack of training and information provided by the authorities to local citizens, as the only preparedness activity associated with the municipality and the civil protection service was the occasional distribution of tide calendars. Furthermore, the need for training was strongly perceived by shopkeepers, especially in the area near the Porto Canale: here the effects of floods are most frequent and training was perceived as a way to reduce damages.

Slightly more than half of participants $(54 \%)$ had direct experience of flooding. These had suffered only moderate economic damage $(M=5.6, \mathrm{SD} \pm 3.39)$, with higher rates of perceived disruption $(M=6.1, \mathrm{SD} \pm 3)$. Moreover, respondents who had already experienced a flood claimed to be more informed about the problem $(\mathrm{Mdn}=5)$ than were other participants in the survey $(\mathrm{Mdn}=3, U=5132, p<0.05$, $r=0.14$ ). Informal interviews revealed that economic damage consisted, for example, of wasted goods in shops and restaurants and, in one case, a car that was swept into the canal harbour. The disruption was slightly higher in events that blocked people's normal routines, even among those who were located relatively far from the areas of greatest and more frequent flooding. Low levels of institutional support were highlighted $(M=3.2, \mathrm{SD} \pm 2.35)$. In particular in the shops of the town centre, people pointed out the absence of economic support for those who had experienced damage, while it was surprising to hear in a small town that authorities were not perceived as active, for example they did not have much direct contact with people before or after critical periods. Furthermore, these data are in line with the overall perception of responses to flooding. Those of the port authority were judged inadequate $(M=4.8, \mathrm{SD} \pm 2.85)$, as were those of the civil protection and municipality $(M=4.9, \mathrm{SD} \pm 3)$ and the emergency medical services $(M=5.4, \mathrm{SD} \pm 2.76)$. In contrast, fire fighters were considered to have been effective in floods $(M=6.2, \mathrm{SD} \pm 2.88)$. Informal interviews made an interesting point about the intervention of the civil protection service, as volunteers were perceived as "good people, willing to help others" but constant problems of coordination were attributed to failures in the municipal government.

Respondents with past experience of floods claimed to be significantly more prepared to cope with a future event (Mdn $=4, U=5037, p<0.05, r=-0.15)$ and significantly more able to protect their families $(\mathrm{Mdn}=5) \mathrm{com}$ pared with people with no experience $(\operatorname{Mdn}=3, \operatorname{Mdn}=4$, $U=4977.5, p<0.05, r=-0.16$ ). A positive relationship was found between how much people felt they were supported by institutions and the perceived level of information received $\left(r_{s}=0.2, p<0.05\right)$ and their preparedness for flooding $\left(r_{s}=0.22, p<0.05\right)$. A Mann-Whitney Test revealed that respondents who knew about evacuation routes were more informed about flooding risk $(U=3553$,
Table 1. Visual output of the key variables.

\begin{tabular}{lll}
\hline Variable & $\begin{array}{l}\text { Mean } \\
\text { value }\end{array}$ & $\begin{array}{l}\text { Standard } \\
\text { deviation } \\
\text { (SD) }\end{array}$ \\
\hline Information & 4.3 & \pm 2.70 \\
Preparedness & 4 & \pm 2.72 \\
Economic damages & 5.6 & \pm 3.39 \\
Disruption & 6.1 & \pm 3 \\
Institutional support & 3.2 & \pm 2.35 \\
\hline
\end{tabular}

$p<0.0001, r=-0.28)$ and felt more supported by the institutions $(U=1110.5, p<0.005, r=-0.27)$. However, these characteristics were not associated with the experience of previous events. This evidence is of particular interest in our research, as at the time of the interviews the municipality of Cesenatico did not have an evacuation plan. According to the informal interviews, the most informed people were likely be more aware of the correct way to leave town. We can also argue that, as no plan was actually implemented by the municipal government, only people who felt more supported by the institutions were likely to have received direct information about unofficial escape routes. However, this explanation cannot be considered as satisfactory, and those particular dynamics should be verified by further, more focused research. Table 1 summarizes in graphical output the key values about information and experience that emerged in this part.

\subsection{An in-depth analysis of warning systems: the alert siren and the SMS warning service in Cesenatico}

The first warning service to be analysed is the flood alert siren activated by the municipal government. During their lifetimes, respondents heard it on average four times $(\mathrm{SD} \pm 4.21$; mode $=0)$ but nearly one-third $(34 \%)$ of respondents had never heard it. A Mann-Whitney test verified that people who had experienced floods appeared to have heard the siren much more often $(\mathrm{Mdn}=5)$ than people who had never had such an experience (Mdn $=0, U=3549.5$, $p<0.001, r=0.39$ ). However, hearing the flood alert siren was not correlated with risk perception, receipt of information, support by institutions or level of damage and discomfort. The number of times the siren was heard is weakly correlated with overall information levels $\left(r_{s}=0.27\right.$, $p<0.001)$, preparation $\left(r_{s}=0.24, p<0.001\right)$ and ability to protect oneself and one's family $\left(r_{s}=0.19, p<0.01\right)$. Citizens who lived near the beach $(\mathrm{Mdn}=4)$ heard the siren more often than others $\operatorname{did}(\mathrm{Mdn}=2, U=4093.5, p<0.05$, $r=-0.18$ ).

The three most common reactions after hearing its sound were to warn other people (29\%), to search for further information $(23 \%)$ and to activate measures for the protection of property $(21 \%)$. A substantial $18 \%$ of respondents did nothing, while small numbers $(3 \%)$ took shelter 
Table 2. Actions taken after hearing the alert siren.

\begin{tabular}{lr}
\hline Action & $\begin{array}{r}\% \text { of } \\
\text { respondents }\end{array}$ \\
\hline Warning of others & 29 \\
Research information & 23 \\
Measures of protection & 21 \\
Did nothing & 18 \\
Shelter & 3 \\
Evacuate & 2 \\
\hline
\end{tabular}

and prepared to evacuate $(2 \%)$. Table 2 provides a graphic overview of the reactions to the alert siren. The behaviour chosen after hearing the sound of the warning is not explained by perception of risk, information, level of support from institutions and level of damage or discomfort. However, a Kruskal-Wallis test revealed a significant difference in level of preparation to cope with a flood in relation to other actions taken after hearing the siren $(H(1)=9.49$, $p<0.01)$. A Mann-Whitney test with a Bonferroni correction $(\alpha=0.017)$, performed as a follow-up to this result, showed that people who engaged in self-protective behaviour $(\mathrm{Mdn}=4)$ felt more able to cope with flooding compared to those who engaged in passive behaviour ( $\mathrm{Mdn}=1, U=293$, $p<0.005, r=0.36$ ). Furthermore, people who engaged in passive behaviour $(\mathrm{Mdn}=1)$ considered themselves less prepared to face flooding with respect to people who were active $(\mathrm{Mdn}=4, U=986, p<0.05, r=0.2)$. There is no association between the extent to which people felt supported by institutions and the actions they took after they heard the siren. No differences related to gender or age were found.

Informal interviews verified the existence of an informal dissemination channel integrated into the official one, namely groups of people that took it upon themselves to warn people. As searching for information is a natural instinct in disasters, various shopkeepers who activated measures of self-protection, such as the installation of mobile bulkheads or placing goods in higher places, reported the need for training on possible alternative protection strategies. Finally, among the citizens who did nothing, some of their shortage of motivation was related to lack of knowledge about possible measures, a lack of knowledge of the risks or, in one case, the belief that "when you hear the siren, the water has already arrived." A different explanation can be found for low rates of evacuation, which may be a function of relatively low danger of flooding in terms of loss of life, but it also responds to the absence of a formal evacuation plan for Cesenatico.

Observations of a more general kind concern the alert via SMS. In our case, the service was complementary to the alert siren and was intended to balance its limitations. However, its existence was known by much fewer citizens than those who stated that they had heard the siren at least

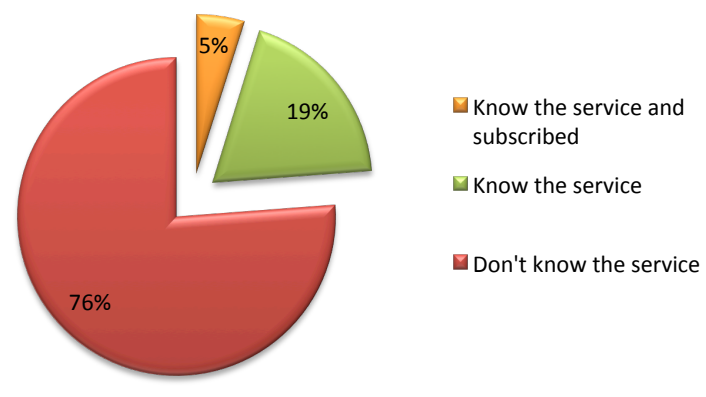

Figure 3. Knowledge of the SMS warning service in Cesenatico.

once in their lives (Fig. 3). SMS warning services were known by only $20 \%$ of all respondents, of whom only a small minority $(5 \%)$ had subscribed to the service. Even if $80 \%$ of them had never heard of it, most of the respondents rated the alert as generally useful $(M=7.3, \mathrm{SD} \pm 2.68)$. Despite this, there is a significant difference among age groups $(\mathrm{G} 1=18-35 ; \mathrm{G} 2=36-55 ; \mathrm{G} 3=55+; H(1)=8.71$, $p<0.05)$. G1 $(\mathrm{Mdn}=7)$ rated the alert less useful compared to $\mathrm{G} 3(\mathrm{Mdn}=9, U=234, p<$ Bonferroni correction $\alpha=0.017, r=-0.36)$. Moreover, a Jonckheere test revealed a significant ascending trend in the median values across the three age groups $(\mathrm{G} 1=7 ; \mathrm{G} 2=8 ; \mathrm{G} 3=9 ; J=3146$, $z=2.86, p<0.005)$.

During informal interviews, a couple of citizens stated that the dissemination of news about the service was ineffective, which is what appears in the quantitative data set. Whether the system was rated as useful was not influenced by knowledge of the service itself, and these data highlight a clear failure in the dissemination process, from which other possible inferences can be derived using by statistical analysis. There is a significant association between knowing about the alert warning system and having experienced a flood $\left(\chi^{2}(1)=4.53, p<0.05, \Phi=0.16\right)$. This corresponds to the belief that respondents who had experienced a flood event were more than 2 times more likely to know the system than those who had not. In addition, interviewees who knew about the system felt significantly more informed $(\mathrm{Mdn}=5)$ than the others did (Mdn $=4, U=2420, p<0.005, r=0.21)$ and felt more supported by institutions $(\mathrm{Mdn}=4)$ than the others $(\operatorname{Mdn}=3, U=935.5, p<0.05, r=0.19)$.

The relations between variables and the knowledge of SMS warning system were investigated by independent $t$ tests and by chi-square ratio. Three main categories of variables (socio-demographic, information and preparedness and past experiences) were used to consider the possible influences of the individual and community dimensions in relation to our literature review. Most results of the $t$ test were not significant and the levels of chi-square have a high probability of random answers for each variable considered. However, the relationship between knowledge of the SMS warning service and previous experience of flooding is confirmed, and this could be related to different levels of risk awareness. 
A further test was used to verify this relationship. Knowledge of the SMS alert system seemed to be affected by the number of times people heard the siren $(U=2652.5, p<0.01$, $r=0.19)$. Respondents who knew the system $(\mathrm{Mdn}=7)$ had heard the siren more often than those who did not $(\operatorname{Mdn}=2)$. Higher levels of perceived institutional support among flood victims are slightly related to knowledge of the SMS warning system, as trust can influence a citizen's decision to subscribe to the public service or pay attention to municipal initiatives in general. Finally, information levels are confirmed as influencing average scores and their relationship with knowledge of the warning system.

The values attributed to the perceived utility of the SMS warning service in Cesenatico are correlated to the main variables that have been used to verify knowledge. Most factors seem to be independent, but there are only weak correlations with age and information levels. Evidence seems to confirm that even if the community generally perceives a service to be useful, actions on information, education and involvement need to be taken to convert a technical instrument into an effective piece of machinery for citizens. Finally, a Mann-Whitney test disclosed that respondents who knew about evacuation routes heard the siren more often ( $U=4456, p<0.05, r=-0.13)$ than those who did not. No association was found between the knowledge of evacuation routes, knowledge of the SMS alert system and the behaviour adopted after having heard the siren. Similarly, no statistically significant correlation was found between knowledge of the SMS warning system, its perceived utility and perception of the effectiveness of structural measures (harbour gates, submerged barriers, rocky cliffs and beach nourishment).

\section{Discussion}

In this section we discuss the results of our research. Findings are compared with existing literature to provide new critical points for scholars to consider. The focus will be on how experience and information can be related with alert services, as we will consider them key aspects that could influence the effectiveness of warnings. Please note that risk perception will be included in the discussion, but further research about its relations with alert services could be desirable.

\subsection{Context, information and experience}

The low perceived effectiveness of structural mitigation measures is likely to be determined by the local flood history, where events were recurrent despite the technical solution adopted. Similarly, the perception of economic damages and disruptions are in line with the ones expected from the description of floods risk in Cesenatico. Low levels of preparedness are related to information, which is a clear driver that determines the effectiveness of non-structural mitigation measures at large (Lindell et al., 2007). The relationship between knowledge of evacuation routes and levels of preparedness revealed by our results can be compared with similar evidence, associated with high levels of worry, obtained by Bradford et al. (2012), who interviewed people in Belgium, Finland, Germany, Ireland and Italy $(n=1231)$. Regarding information and preparedness, their research had similar results to ours, as only $34 \%$ of their participants considered themselves prepared for future floods. Bradford et al. (2012) also suggested that the authorities should increase confidence by providing specific information on which practical mitigation measures need to be adopted by citizens. In our opinion, the different values attributed to information sources demonstrate that no single channel of communication is likely to reach all people and, in any case, it will have to be integrated with word-of-mouth communication (Alexander, 2002).

We argue that in our case study the total absence of drills was particularly critical. Villagrán de León (2012) suggested that drills and exercises involving all components of warnings and all stakeholders are a critical means of identifying additional gaps, increasing awareness of how the system works and improving interactions among people within and external to the communities. Similarly, the data set analysed by Salit et al. (2013) seems to suggest that in many cases information could be improved by advice on how to behave in a crisis situation. Our other findings about experience and floods are in line with the literature, which generally recognizes the relationship between experience and perceived vulnerability (Lara et al., 2010). The use of specific questions about flood warning allows us to discuss other correlations between information, preparedness and non-structural mitigation measures.

\subsection{The alert siren and the SMS warning service in Cesenatico}

The data about the alert siren verified the results of Alexander (2002): the siren is a simple instrument that has the benefit of immediacy and can be used both during daytime and at night but can also be easily ignored, not heard or misinterpreted. Alert sirens have localized effects that may depend on contextual factors that can prevent people from hearing them, for example due to a citizen's activities or his or her level of awareness. Moreover, our data provide further evidence for discussion. The first point to analyse is what the behaviour related to the alert siren may really signify. Positive or constructive reactions are more common than in many other cases recently defined in other contexts, such as in Romania, where about $52 \%$ of people took some kind of action after the reception of a warning (Salit et al., 2013). The high levels of social capital could be a possible explanation for this, because its influence could be also be related to the existence of informal dissemination channels through which particular groups warn people. As our background data were scarce in that direction, further research should investigate these aspects more thoroughly. Instead, other reactions reflect com- 
mon responses such as the sealing up of certain structures to keep water out (Smith and Petley, 2009). The high proportion of people who search for information after hearing the siren reflects the fact that citizens' behaviour is orientated by specific knowledge about the event and by access to information about measures of protection that emphasize how to use the time gained by warning in order to produce an effective response, while in other cases insecurity and stress may limit the ability to react (Parker et al., 2007). The effectiveness of warning is better when people have more detailed knowledge about self-protection measures that they can undertake as a pre-condition for action (Thieken et al., 2007).

It is interesting to compare our results with the study by Fielding et al. (2007), which used a list of actions and categories to illustrate the different levels of flood warning in the UK (flood watch, flood warning and severe flood warning). When "flood warning" is considered, $44 \%$ of respondents would undertake measures related to the protection of property, $42 \%$ would prepare to evacuate and $10 \%$ would do nothing or would not know what to do. Warning and helping others would be undertaken by $8 \%$ of respondents. When actions in "severe flood warning" situations are considered, $63 \%$ of respondents reported that they would prepare to evacuate or safeguard people and animals. Fewer than $10 \%$ would warn or help others, while $6 \%$ would do nothing. This evidence highlights the particular role of positive behaviour in Cesenatico, as we observed three kinds of answers related to "warning others" that are likely to be related to the existence of informal warning channels and specific cultural patterns that are probably a function of social capital. Conflicting results on evacuation are likely to be a function of different local flood histories but are also related to the absence of evacuation plans. Similar forms of inaction can be found in both our data and the study by Fielding et al. (2007), mostly at the "flood warning" level. Our data offer a particular point of view on the debate about the relation between risk perception and adoption of preparedness measures. On the one hand, some authors associate high levels of risk perception with the adoption of precautionary measures and positive behaviour, for example in work on information sources (Miceli et al., 2008). On the other hand, research points out that flood risk awareness does not necessarily imply the adoption of protection measures (Burningham et al., 2008). Our data tend to show that positive behaviour is present in the search for information and the activation of particular protection measures. Similarly, the existence of informal dissemination channels for warnings, cross-checked with the presence of social capital, refers a social situation that could respond to stimulation. A critical element that could orient this attitude is one defined by O'Sullivan et al. (2012) according to whom flood information is usually disseminated on a top-down basis, offering little opportunity for the overall reception of constructive feedback from end users. These negative factors are likely to reduce institutional trust, as reciprocity is related to perceived accountability. Similarly, Parker and Priest (2012) suggested that further progress is needed in order to increase trust-building partnerships throughout the chain of warning, while wider community and individual engagement are still critical elements that need improvement, whatever the technology used.

Our results seem to support the assertion that no differences in reaction exist among genders or age groups, despite Parker and Priest's (2012) discussion of other studies that show such things. The results reported by Fielding et al. (2007) show similar intentions of males and females, but men were regarded as more likely to undertake positive behaviour, such as preventing the ingress of water, and woman were more likely to seek further information. We found no correlation between age groups and actions, while Fielding et al. (2007) noted that the youngest and oldest age groups tended to have a lesser assessment of risk and to take fewer actions.

Different evidence emerges from data on the SMS warning service. The result shows that the development of technical instruments is not sufficient in itself to create a good warning if the population is not involved and the service is not tailored to the characteristics and culture of the community. On the one hand, our data verify what has already been shown by Kreibich et al. (2007). Warnings can be considered favourably even when they do not reach a large portion of the citizenry. On the other hand, we show that the utility of warnings is independent of the perceived effectiveness of structural measures and also of demographic elements such as age. Similarly, Parker et al. (2009) suggested that to have a positive impact, technological advancement depends on the adoption of shared considerations among flood managers and communities regarding the behavioural aspects of the warning process. Inclusive management and governance is fundamental, as it increases trust in agencies and develops messages focused on local needs, experiences and communication modes. Missing an appropriate opportunity for dissemination is thus a critical point that has the potential to waste the benefits derived from the development of a warning system. The statistical relations between the SMS warning and alert siren could be related to the complementary role of the services but also to other elements. Indeed, the presence of the acoustic signal can increase risk perception, while its location may require a higher presence of emergency personnel (e.g. civil protection operatives) and in general a greater presence on the ground of representatives of the main local institutions.

\section{Conclusions}

Our case study shows in detail how different experiences and information provide an essential background that enables us to understand the critical interactions that affect warning services. We registered the presence of common failures that can be related to how vulnerability is treated in society. Even 
if we assume that forecasting problems exist, as shown in the literature (Llasat and Siccardi, 2010), we found that the contextualization of warnings can critically modify the effects of the technical instruments upon the community. We believe that many relationships present points of interest for scholars, but we would like to highlight the following points in particular:

- Lack of information seems to play a crucial role in determining the local lack of preparedness. Citizens that experienced previous floods were more informed but also accorded low values to the emergency responses of the municipal government and civil protection services. Similarly, the possible evacuation roads were associated with individual preparedness more than with the collective equivalent. We argue that a lack of drills could be a determinant of such patterns and that they reveal a lack of communication between the authorities and local citizens.

- We found that the first reactions to the alert siren differed from what the literature usually associates with warnings. The number of respondents who warn others is significantly higher, while evacuation values are lower. These elements can be related to specific local features, such as the existence of informal warning channels, the nature of recurring floods and probably also the absence of evacuation plans, but they are not related to the perception of level of support by local institutions during floods. We argue for the influence of social capital, but further research is needed in order better to understand this particular point.

- No difference in gender and age influenced the reactions to the alert siren, but age was correlated with the perceived utility of the SMS warning service.

- Warning services, such as an SMS, may be perceived as very useful even if they are not tested. In fact, the literature attributes importance to the existence of warnings in their own right. However, our data highlight the contrast between high utility levels and critical failures in the dissemination process that can seriously compromize the role of technical services.

- We found evidence of positive behaviour, such as the search for information and activation of particular flood prevention measures. However, their effectiveness may be limited by the absence of specific training, such as drills.

Our data set has limitations, but it does not seem to invalidate our results. It may include an occasional lack of rigour, for example in our inability to compute a response rate for the completion of questionnaires, while informal interviews and direct observation may add to this problem. Some concerns are related to the collection of data in two different periods,
2011 and 2012, but we used the statistical analysis to show that no significant differences exist between the two data sets.

To sum up, our case study shows that the effectiveness of warnings can be related to how they are developed in the community rather more than to the technical elements alone. Warnings can be perceived as effective technical solutions, but nevertheless the dimensions of information, training and involvement may be missing. From our data, we argue that the community tries to increase its preparedness by accessing information, but the authorities do not support this process with concrete practices, or simply do not do so properly. This could be related to cultural patterns and to the particular floods that occur in the Adriatic Sea, but other research should test our results in different case studies around the Mediterranean.

For the moment, we simply confirm the evidence provided by Kelman (2001): the stimulation of comprehensive education on natural hazards, local risks and effective protection actions are necessary to produce effective changes in citizens' ways of living and to improve comprehensive flood management. In the future, scholars should further investigate the relationship between perceived low levels of institutional support and the absence of training processes, as well as the missing dimension of perceived accountability. These points are particularly critical in the Mediterranean area, where culture and the accountability of institutions are sensibly different from what they are in central and northern Europe. Similarly, our case study suggests the need for a wider analysis of how policies, politics, social capital and effective deployment of warning systems interact. Even if flood warnings should involve new procedures to include the community and increase the effectiveness of dissemination process, this may not be enough without a wider reflection on how to ensure the accountability of flood management. This could be a critical issue not only for providing effective answers to the population's needs but also for the creation of a new culture that is able to maximize technical advancements and create wider social progress in effective disaster risk reduction.

Acknowledgements. The authors gratefully acknowledge David Alexander (University College London) for his time, lessons and trust. This paper would not exist without him, his supervision and the Institute for Risk and Disaster Reduction.

We wish to thank Carlo Tramontano (University of Coventry) for his precious feedback and support, as well as the editor of the special issue of NHESS, Paolo Ciavola, and the anonymous reviewers for their commitment to improving our paper.

A special acknowledgement is due finally to THESEUS Project ("Innovative technologies for safer European coasts in a changing climate" FP7.2009-1, contract 244104), its coordinator, Barbara Zanuttigh, who genuinely supported this work, the volunteers of Radio Soccorso Cesenatico for their commitment in helping others and the Psychology of Emergency Group at University of Bologna for the use of data sets. 
Edited by: P. Ciavola

Reviewed by: P. Ciavola and two anonymous referees

\section{References}

Alexander, D.: Natural Disasters, CRC Press, Taylor \& Francis Group, Boca Ranton, FL, 632 pp., 1993.

Alexander, D.: Principles of Emergency Planning and Management, Terra Publishing, Dunedin Academic Press, Edinburgh, UK, 340 pp., 2002.

Armaroli, C., Ciavola, P., Perini, L., Calabrese, L., Lorito, S., Valentini, A., and Masina, M.: Critical storm thresholds for significant morphological changes and damage along the Emilia-Romagna coastline, Italy, Geomorphology, 143-144, 34-51, 2012.

Bradford, R. A., O’Sullivan, J. J., van der Craats, I. M., Krywkow, J., Rotko, P., Aaltonen, J., Bonaiuto, M., De Dominicis, S., Waylen, K., and Schelfaut, K.: Risk perception - issues for flood management in Europe, Nat. Hazards Earth Syst. Sci., 12, 2299-2309, doi:10.5194/nhess-12-2299-2012, 2012.

Burningham, K., Fielding, J., and Thrush, D.: 'It'll never happen to me': understanding public awareness of local flood risk, Disasters, 32, 216-238, doi:10.1111/j.1467-7717.2007.01036.x, 2008.

Cartocci, R.: Mappe del Tesoro-Atlante del Capitale Sociale In Italia, Il Mulino, Bologna, 157 pp., 2007.

Ciavola, P., Ferreira, O., Haerens, P., Van Koningsveld, M., and Armaroli, C.: Storm impacts along European coastlines, Part 2: lessons learned from the MICORE project, Environ. Sci. Policy, 14, 924-933, doi:10.1016/j.envsci.2011.05.009, 2011.

De Leeuw, E. D.: To Mix or Not to Mix Data Collection Modes in Surveys, J. Offic. Stat., 21, 233-255, 2005.

Fielding, J., Burningham, K., Thrush, D., and Catt, R.: Public Response to flood warning, R \& D technical report SC020116, Joint Defra/Environment Agency Flood and Coastal Erosion Risk Management R \& D Programme, Environment Agency, Bristol, UK, 119 pp., available at: http://www.environment-agency.gov. uk (last access: 30 March 2015), 2007,

Gruntfest, E.: Nonstructural Mitigation of Flood Hazards, in: Inland Flood Hazards: Human Riparian and Aquatic Communities, Cambridge University Press, Cambridge, UK, 394-410, 2000.

Guha-Sapir, Hoyois, P., and Below, R.: Annual Disaster Statistical Review 2012, Centre for Research on the Epidemiology of Disasters (CRED), Université Catholique de Louvain, Louvain, Belgium, 50 pp., available at: http://www.cred.be (last access: 30 March 2015), 2013.

Handmer, J.: Improving Flood Warning in Europe: a research and policy agenda, Environ. Hazards, 3, 19-28, doi:10.1016/S14642867(01)00010-9, 2001.

Il Giornale della Protezione Civile: Rassegna Stampa del 07/03/2011, Il Giornale della Protezione Civile, available at: http://www.ilgiornaledellaprotezionecivile.it/bf/ filesupload/rassegna_stampa_protezione_civile_7_marzo_

2011_CENTRO_43081.pdf (last access: 5 October 2014), 2011.

Kelman, I.: The autumn 2000 floods in England and flood management, Weather, 56, 346-360, doi:10.1002/j.14778696.2001.tb06507.x, 2001.
Kreibich, H., Müller, M., Thieken, A. H., and Merz, B.: Flood precaution of companies and their ability to cope with the flood in August 2002 in Saxony, Germany, Water Resour. Res., 43, 1-15, doi:10.1029/2005WR004691, 2007.

Lara, A., Saurí, D., Ribas, A., and Pavón, D.: Social perceptions of floods and flood management in a Mediterranean area (Costa Brava, Spain), Nat. Hazards Earth Syst. Sci., 10, 2081-2091, doi:10.5194/nhess-10-2081-2010, 2010.

Leonard, S. G., Johnston, D. M., and Gregg, C. E.: Warning systems, in: Encyclopedia of Natural Hazards, Springer, Berlin, Germany, 2012.

Lindell, M. K., Prater, C., and Perry, R. W.: Introduction to emergency Management, Wiley, Hoboken, NJ, 624 pp., 2007.

Llasat, M. and Siccardi, F.: A reflection about the social and technological aspects in flood risk management - the case of the Italian Civil Protection, Nat. Hazards Earth Syst. Sci., 10, 109-119, doi:10.5194/nhess-10-109-2010, 2010.

Martinelli, L., Zanuttigh, B., and Corbau, C.: Assessment of coastal flooding hazard along the Emilia Romagna littoral, IT, Coast. Eng., 57, 1042-105, doi:10.1016/j.coastaleng.2010.06.007, 2010.

Miceli, R., Sotgiu, I., and Settanni, M.: Disaster Preparedness and Perception of Flood Risk: A Study in an Alpine Valley in Italy, J. Environ. Psychol., 28, 164-173, doi:10.1016/j.jenvp.2007.10.006, 2008.

O’Sullivan, J. J., Bradford, R. A., Bonaiuto, M., De Dominicis, S., Rotko, P., Aaltonen, J., Waylen, K., and Langan, S. J.: Enhancing flood resilience through improved risk communications, Nat. Hazards Earth Syst. Sci., 12, 2271-2282, doi:10.5194/nhess-122271-2012, 2012.

Parker, D. J. and Priest, S. J.: The Fallibility of Flood Warning Chains: Can Europe's Flood Warnings Be Effective?, Water Resour. Manage., 26, 2927-2950, doi:10.1007/s11269-012-0057-6, 2012.

Parker, D. J., Tapsell, S. M., and McCarthy, S.: Enhancing the human benefits of flood warnings, Nat. Hazards, 43, 397-414, doi:10.1007/s11069-007-9137-y, 2007.

Parker, D. J., Priest, S. J., and Tapsell, S. M.: Understanding and enhancing the public's behavioral response to flood warning information, Meteorol. Appl., 16, 103-114, doi:10.1002/met.119, 2009.

Penning-Rowsell, E. C. and Tapsell, S.: Coping with extreme floods: warnings, impacts and response, Int. Assoc. Hydrol. Sci., 271, 379-383, 2002.

Penning-Rowsell, E. C., Tunstall, S. M., Tapsell, S. M., and Parker, D. J.: The Benefits of Flood Warnings: Real But Elusive, and Politically Significant, Water Environ. J., 14, 7-14, doi:10.1111/j.1747-6593.2000.tb00219.x, 2000.

Perini, L., Calabrese, L., Deserti, M., Valentini, A., Ciavola, P., and Armaroli, C.: Le mareggiate e gli impatti sulla costa in Emilia Romagna 1946-2010, I quaderni di Arpa, Arpa Emilia Romagna, Italy, 141 pp., 2011.

Phillips, B. D.: Qualitative disaster research, Understanding qualitative research, Oxford University Press, Oxford, UK, 192 pp., 2014.

Putnam, R. D., Leonardi, R., and Nanetti, R. Y.: Making Democracy Work: Civic Traditions in Modern Italy, Princeton University Press, Princeton, NJ, 280 pp., 1993. 
Regione Emilia Romagna: Nuovi strumenti per la gestione dei litorali in Emilia-Romagna, edited by: Montanari, R. and Marasmi, C., Servizio Difesa del Suolo della Costa e della Bonifica, Regione Emilia Romagna, Bologna, Italy, 70 pp., 2011a.

Regione Emilia Romagna: Studio per ottimizzare la gestione del litorale di Cesenatico Nord, edited by: Preti, M., Regione Emilia Romagna, Bologna, Italy, 196pp., available at: http://ambiente.regione.emilia-romagna.it/suolo-bacino/ sezioni/studi/difesa-del-suolo-della-costa-e-bonifica (last access: 30 March 2015), 2011b.

Russell-Bernard, R.: Research Methods in Anthropology, Altamira Press, New York, NY, 803 pp., 2006.

Salit, F., Zaharia, L., and Beltrando, G.: Assessment of the warning system against floods on a rural area: the case of the lower Siret River (Romania), Nat. Hazards Earth Syst. Sci., 13, 409-416, doi:10.5194/nhess-13-409-2013, 2013.
Smith, K. and Petley, D.: Environmental Hazards. Assessing Risk and reducing disaster, 5th Edn., Routledge, New York, NY, 416 pp., 2009.

Tabachnick, B. G. and Fidell-Allyn, L. S.: Using Multivariate Statistics, Pearsons International, New York, NY, 1008 pp., 2006.

Tapsell, S.: Socio-Psychological Dimensions of Flood Risk Management, in: Flood Risk Science and Management, Wiley-Blackwell, Oxford, UK, 407-428, doi:10.1002/9781444324846.ch20, 2010.

Thieken, A. H., Kreibich, H., Müller, M., and Merz, B.: Coping with floods: preparedness, response and recovery of flood affected residents in Germany in 2002, Hydrolog. Sci. J., 52, 1016-1037, doi:10.1623/hysj.52.5.1016, 2007.

Villagrán de León, J. C.: Early warning principles and systems, in: Handbook of Hazards and Disaster Risk Reduction, Routledge, London, UK, 481-492, 2012. 